\title{
Development of Ubiquitous On-Demand Study Support Environment for Nursing Students
}

\author{
Yukie Majima $^{1}$, Yumiko Nakamura ${ }^{2}$, Yasuko Maekawa ${ }^{2}$, and Yoichiro So $^{3}$ \\ ${ }^{1}$ Department of Liberal Arts and Science, Osaka Prefecture University \\ 1-1 Gakuencho, Naka, Sakai, Osaka 599-8531, Japan \\ majima@las.osakafu-u.ac.jp \\ ${ }^{2}$ School of Nursing, Osaka Prefecture University \\ 3-7-30 Habikino, Habikino, Osaka 583-8555, Japan \\ naka-yuanursing.osakafu-u.ac.jp, \\ yasuko_m@nursing.osakafu-u.ac.jp \\ ${ }^{3}$ Production Systems Research Lab. KOBELCO \\ 1-5-5 Takatsukadai, Nishi, Kobe, Hyogo 651-2271, Japan \\ sou.youichirou@kobelco.com
}

\begin{abstract}
We were selected to work with "Development of e-Learning Program to help enhance human resource ability based on needs," which is a government supported program of fiscal year 2005 to address modern education needs (Modern GP). The program has therefore been underway since 2005. The objectives of the program are to use e-Learning to further improve education and teaching practices qualitatively for nursing education, to supply high-level nursing practice capabilities, and provide a new environment in which students can study independently in an efficient manner. The main targets to achieve the program goals are: i) to produce e-Learning training materials that include examples of nursing to use for the study of nursing practice and support students' acquisition of problem-solving abilities during nursing operations; and ii) to construct an environment to support ubiquitous on-demand studies in which students can study for themselves easily, at any time, and anywhere on campus or on the actual practice site using this e-Learning methodology. This paper presents a report of an actual lecture class conducted in using such training materials.
\end{abstract}

Keywords: Education of nursing, Nursing practice ability, E-learning, Ubiquitous on-demand study.

\section{Introduction}

As medical treatment levels are becoming more advanced and patients' requirements become increasingly diverse, what is requested now by every organization that is taking part of nursing education is the need to better cultivate human resources to work in nursing positions so that they can gain proper proficiency in nursing practice, which means the ability to assess a patient's situation correctly, then understand and provide the most appropriate nursing care to that patient. To respond to that social need for human resources, we believe that it is necessary to improve the education 
and instruction of nursing more qualitatively, and to provide students with a new environment in which they can study efficiently.

Among all educational activities, the most effective way for students to acquire actual nursing capabilities is to have the learner join on-site practice training, which is arequired part of the nursing education curriculum. Through on-site practice, students can learn comprehensively by communicating directly to patients or those who require nursing care. However, such practicing facilities are spread out in various locations. For that reason, the situation available on site is not necessarily as good a study environment as that available on campus. The campus might provide facilities such as libraries, Internet capability, and IT equipment. By making e-Learning available at every on-site practice location, we believe that we can not only improve the study environment situation, but also help to raise the quality level of the study itself.

Under these circumstances, the School of Nursing at the Osaka Prefecture University was selected to work with "Development of e-Learning Program to help enhance human resource ability based on needs," which is a government-supported program of fiscal year 2005 to address modern educational needs (Modern GP). The actual title is "e-Learning to help acquire nursing practice ability -Construction of a ubiquitous on-demand study supporting environment-." The program began activities last year as the "CanGo" project. "CanGo" stands for "Communication", "Árt", "Nursing", "Good practice", "Osaka Prefecture University".

This paper reports the actual classes taught in 2006-2007 using materials that were developed specifically for this project based on project activities undertaken in 2005, and of the results obtained from on-site training support we gave to students.

\section{CanGo Project Summary}

The CanGo project objective is to fill the gaps that are readily noticeable from one study method to another, to improve the efficiency and usefulness of every study activity on-campus or off-campus, and to improve students' attitudes toward study more aggressively. This objective must be achieved so that students can acquire the ability to solve study-related problems that might often occur in lectures, or during practice sessions made on-campus or on-site, all of which are conducted in the regular curriculum of nursing education.

The backbones of our activities are: i) to produce e-Learning materials for the study of nursing practice and examples for use by students to acquire problem-solving ability; and ii) to construct a ubiquitous on-demand study-supporting environment in which students can study independently through e-Learning at any time, anywhere, and without any difficulty whatsoever. Through these four-year studying opportunities on and off campus, we are hoping to help students acquire capabilities to solve all kinds of nursing problems efficiently and aggressively so that, eventually, we can produce in our society good human resources with full proficiency in advanced nursing practice capabilities.

Specifically, the following three unique environments are available to support students' study. 
Utilizing USB memory that stores the recorded study history, anyone can easily download examples of nursing from the nursing training materials server machine. Each student is allowed to compile a digital nursing dictionary by downloading the necessary sub-training materials before the on-site practice starts. We believe that any student can study independently while compiling such a "personal digital nursing dictionary." During that study process, a learner would be able not only to review and summarize the contents of past study, but also to proceed with meta-recognition that would point to further study or related activities, and what knowledge and nursing technology must be acquired before the on-site practice starts. Finally, to support selfstudy, a bi-directional study support environment would be prepared in which a

\section{e-Learning Supports Acquiring Practical Nursing Ability}

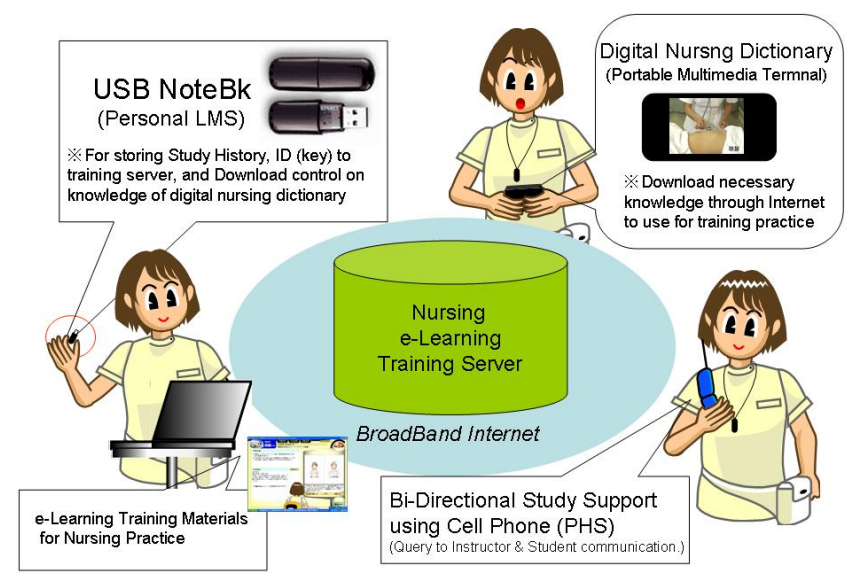

Fig. 1. Overall structure of CanGo project

Table 1. CanGo project targets and its accomplishments

\section{Targets}

1) Develop 100 examples of nursing by re-structuring the existing nursing examples documents, and construct a training-material database

2) Construct a ubiquitous on-demand study support environment that is openly available to students

\section{Accomplishments}

1) Development of 107 examples in four specialized nursing areas, and a total of 1901 references for the digital nursing dictionary

2) Supplying equipment for study support environment 272 portable multimedia terminals

15 laptop PCs to support lecture classes

1 wireless attachment for a projector 
student can receive guidance from the instructor through e-mail that might be available using a cell phone or other media equipment. Figure 1 depicts the overall structure of the CanGo project. Table 1 shows its targets.

\section{3 e-Learning Materials for Nursing Examples Simulation}

We produced nursing training materials with examples for each specialized nursing area based on prototype training frames for e-Learning of nursing, developed by Majima et. al. and Seta et. Al.[1,2,4,5] to improve nursing students' problem-solving abilities.

\section{e-Learning Training Materials}

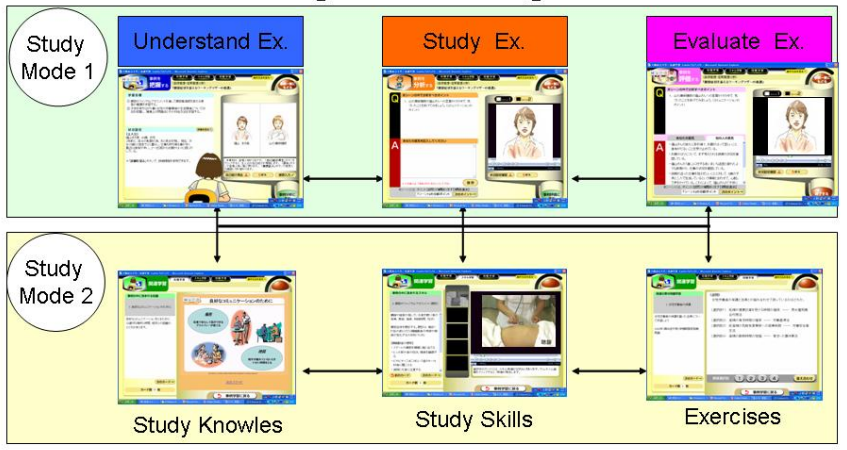

Nursing Practice Examples (Nursing Process) of "Basic Nursing Knowledge", "Basic Nursing Techniques" and "National Examinations" are studied through e-Learning.

Fig. 2. Training frames on nursing examples

Portable Multimedia Terminal (Digital Nursing Dictionary)
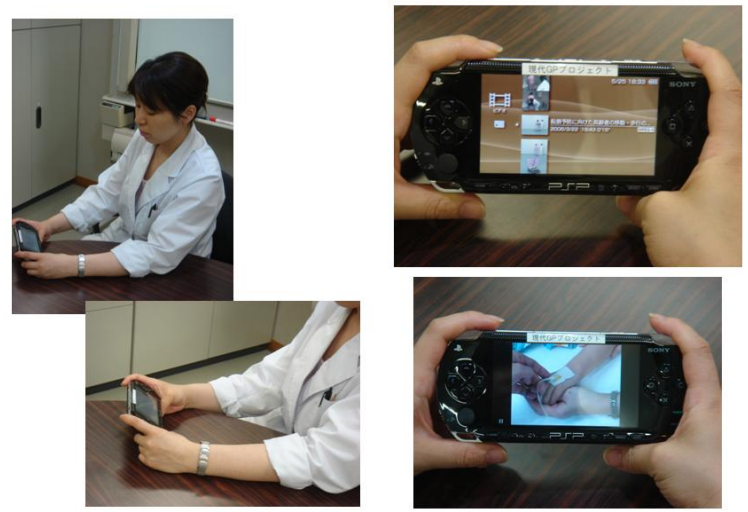

Skill Image Screen

Fig. 3. Digital nursing dictionary 
Training frames (Figure 2) consist of two study modes. In study mode 1, a series of nursing processes can be studied through "Understanding patients' examples", "Problem studies on nursing", and "Evaluation of analyzed results". Study mode 2 is available for each example of a patient, in which the student can self-study, when necessary, through the contents of basic and required knowledge of specialized nursing practices, nursing techniques, and national-examination-related materials. Training materials were produced using multimedia techniques incorporating sound effects, animation, and illustrations. Contents that are organizing the training materials can be reorganized and reused for other digital sub-training materials, allowing the creation or addition of any new training materials without difficulty.

Moreover, after downloading, they can be used to create a new digital nursing dictionary (Figure 3). In the other mobile method, Maag[3] introduced an emerging technology using by podcasting in nursing education.

\section{Practice and Example in Nursing Education}

From 2006 to 2007, we hosted a series of lectures using training materials developed in from 2005 to 2007, and used portable multimedia terminals for on-site practice. Following are the ideas and opinions given to us after that on how to improve practices, as well as other useful advice.

\subsection{Lectures Using Training Materials with Nursing Examples}

Instructors who joined in the creation of training materials actually used them in their classes. We asked them to report about how they used the training materials in their classes in addition to the responses they received from their students. To have them conduct such training in their classes, the study-support environment development team of the project organization supplied the training materials, computers and assemblies, and other materials to instructors who requested them. The execution evaluation team helped create questionnaires for students and the reporting formats to be used by the instructors.

The actual lectures were intended mainly for third-year nursing department students (about 120-140) studying for work in five different nursing fields.

Following are some examples of how training materials were used: i) Starting with the introduction of the patient starring in the training materials of examples on nursing (giving self-introduction narration by the patient), the patient subsequently presented scenes in which nursing problems are described; then the students were separated into work groups and each was expected to make a nursing care plan, and to present it before others, which were finally evaluated by the instructor with appropriate comments provided. ii) Introduction of some nursing examples and scenes of nursing care problems were posed. iii) Providing the students with some nursing care problems beforehand to use them in later work to be done by every group. Therefore, different approaches seem to have been taken by each instructor.

Some opinions from the students are as follows: "It was easy to grasp the images of the examples," "It was easy to read the patient's emotions shown in the examples," "It was realistic, so it was easy to understand," "It was realistic and practical," "It 
was good from a visual perspective with the image pictures provided," "It was easy to know the necessary information," "It was good to hear the information given by voice," and "I was able to understand the priority of the nursing care problems." Additionally some students pointed out not only about how to collect information, but also about the methodology of how nursing-care assistants should recognize situations to move forward to create opportunities to educate patients.

\subsection{On-Site Practice Support by Portable Multimedia Terminals}

We prepared portable multimedia terminals (PSP, Play Station Portable; Sony Corp.) loaded with training material contents prepared for the associated nursing practice areas, and lent them each to students who agreed to monitor them. Subsequently, we requested that they use them during the entire practice period. We requested them to give us opinions regarding the operability of the training materials and other information when they had to return the terminal. Following are some of the comments.

\section{Portable Multimedia Terminal}

1. It was good to be able to find and view the necessary document without taking much time.

2. Because it is basically a game machine, its operability is good.

3. It was easy to use the training materials in this way.

4. The images in the training materials are useful, as if we were playing a game.

5 . It is easy to carry because it is small and light.

6. The screen was easier to see than I thought.

7. The battery power duration time is too short.

8. It would be nice if there were a search function available everywhere in the training materials.

\section{Training Materials' Contents}

1. They were helpful in the practice class. It would have been nice if they had been available before.

2. What we wanted to see out of the training materials was restricted for our practice class.

3. It was very convenient to be able to see technically related pictures close at hand.

4. It was helpful to understand things using images.

5. We can see it anytime anywhere. Therefore, it is helpful when we study at home after the nursing technique practice is over.

\section{Discussions}

After having had the training materials and the contents we produced used in the actual classes, we found that the students' evaluations were good partially because it is something new to them. Nevertheless, their comments and opinions accurately reflected their experience, and helped us to determine the issues clearly and work continuously to correct and improve them in future versions of the system. Some 
instructors were not very happy with manipulation of information equipment, which underscores the importance of support them during use in actual classes. Through the process of having the training materials used in actual classes, we can continue to search for the most appropriate training materials. In so doing, we can review previous teaching methods and adapt and reconstruct them, if necessary. Additionally, using such training materials in actual classes, we can review the class proceedings and teaching methods the classes with the materials combined. Above all, the fact that the instructors felt that teaching a class was fun should create a positive impact on future educational activities resulting in leading to develop of our faculty.

\section{Conclusions}

This report described our introduction of e-Learning in the School of Nursing at the Osaka Prefecture University (as the CanGo project), and reported comments and opinions given when we had the nursing practice example materials and sub-material contents we produced from 2005 to 2007 used for the actual classes from the first half of 2006 to 2007. In addition, we reported those comments and opinions given from the experiences we had when supporting the actual on-site practices.

Future studies will further introduce e-Learning techniques based on the plan, along with regular and constructive review. We would be happy if the knowledge and experience we received were referenced and used anywhere else.

\section{Acknowledgments}

This project was conducted through the aid of the Modern Education Needs Supporting Program of the year 2005 offered from the Ministry of Education, Culture, Sports, Science and Technology.

\section{References}

1. Kazuhisa, S., Yukie, M., Yoichiro, S.: Nursing task ontology based learning system redesign for enabling adaptive on-demand learning environment. In: Proceedings of the 3rd WSEAS/IASME International Conference on Engineering Education, Greece, pp. 114-119 (2006)

2. Kazuhisa, S., Yukie, M., Yoichiro, S.: Towards Building Adaptive On-Demand Learning Environment Based on Nursing Ontology. WSEAS Transaction on Advantages in Engineering Education, 563-570 (2006)

3. Margaret, M.: Podcasting: An emerging technology in nursing education. Studies in Health Technology and Informatics 122, 835-836 (2006)

4. Yukie, M., Yoichiro, S.: Development of E-learning for Problem solving Approach of Nursing Students. Studies in Health Technology and Informatics 122, 919 (2006)

5. Yukie, M., Yoichiro, S., Kazuhisa, S.: Framework for Problem-Solving Based Learning in Nursing Domain - An Experimental Study. Learning by Effective Utilization of Technologies: Facilitating Intercultural Understanding, pp. 625-628 (2006) 